\title{
Diversidade, migrações e inclusão: desafios à gestão e à democracia
}

JAQUELINE MOLL* Universidade Regional Integrada do Alto Uruguai e das Missões, Frederico Westphalen- RS, Brasil.

MARIA CARMEN SILVEIRA BARBOSA

Universidade Federal do Rio Grande do Sul, Porto Alegre- RS, Brasil.

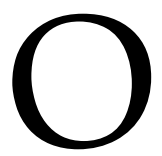
s desafios da educação são desafios de toda sociedade. No contexto da própria afirmação democrática e de nossa capacidade de viver juntos está o do aprendizado da diversidade e o do acolhimento de imigrantes. Em um país como o Brasil, que tem nas suas matrizes povos originários renegados, povos trazidos como escravos e imigrantes, há um caminho a ser construído que precisa dialogar com a capacidade de ressignificar o passado e reescrever o presente, para que o futuro - como dizia Paulo Freire - possa ser transformado.

A escola pública brasileira tem enfrentado muitos temas, um deles é o da diversidade. Inicialmente, é construir o sentido de pertencimento para/com os sujeitos do campo e também das regiões urbanas, o que inclui crianças, jovens e adultos com sua diversidade de histórias pessoais e coletivas, em sua raça, religião, gênero, opções políticas, ideologias. Não tem sido uma tarefa fácil nem para os professores, nem para as famílias, nem mesmo para os próprios sujeitos da educação. Há um caldo cultural de xenofobia e de outras fobias, que é preciso identificar, compreender e enfrentar.

Nos últimos anos, há uma provocação às escolas brasileiras, especialmente as públicas: o tema das novas migrações. Chegam ao país moradores de toda a América Latina, especialmente haitianos, bolivianos, colombianos e venezuelanos. Da América Central vieram os haitianos, da África os congoleses e angolanos, e da Ásia ocidental estão chegando os sírios (ACNUR, Brasil, 2019). Como a escola, a comunidade educativa, o sistema educacional pode se organizar para acolher essa diversidade? Como afirmar a diversidade em um contexto social e político que fomenta a intolerância e aprofunda

* Mestre em Educação pela Pontifícia Universidade Católica do Rio Grande do Sul e Doutora em Educação pela Universidade Federal do Rio Grande do Sul. Atualmente é professora da Universidade Regional Integrada do Alto Uruguai e das Missões. E-mail: <jaquelinemoll@gmail.com>.

* Mestre em Planejamento em Educação pela Universidade Federal do Rio Grande do Sul, Doutora em Educação pela Universidade Estadual de Campinas. Atualmente é Professora Titular da Universidade Federal do Rio Grande do Sul. É editora da Revista Infância Latinoamericana. 
desigualdades econômicas? Compartilhar experiências de gestão educacional pública que acolham a diferença e as migrações é o objetivo desta entrevista ${ }^{1}$, além de outros temas relevantes para a educação pública.

No contexto da Escuela de Verano do Instituto Rosa Sensat de formação de professores, em julho de 2019, Jaqueline Mol, professora titular da UFRGS, professora do PPGEDU/ URI e do PPGEC/UFRGS e Maria Carmen Silveira Barbosa, professora titular da UFRGS, professora no PPGEDU/UFRGS e editora da Revista Infância Latinoamericana realizaram esta entrevista com o professor Miquel Essomba, secretário Municipal de Educação de Barcelona, desde $2015 .^{2}$

\section{Jaqueline Moll (JM) e Maria Carmem Silveira Barbosa (MCSB) - Gostaríamos de ini- ciar falando sobre a sua formação acadêmica, a vida na universidade e a relação com a política. Como esses mundos se cruzam, se retroalimentam e se repelem?}

Miquel Essomba (ME)- De alguma maneira, resumiria minha trajetória acadêmica e política em dois grandes elementos: o primeiro deles, uma dedicação total ao mundo da educação. Eu quis me dedicar à educação desde que tinha oito anos, queria ser professor. É preciso dizer que essa dedicação à educação me custou algumas dificuldades porque as pessoas a minha volta - minha família, meus professores - me diziam que como eu possuía boas qualificações escolares eu não deveria me dedicar à educação porque não era importante, que eu deveria fazer coisas relacionadas às ciências e às engenharias, ou à tecnologia porque tinha total capacidade para fazê-lo. E, apesar de tudo, remando contra essas orientações, me dediquei à educação por toda a minha vida. Recordo que a primeira vez que trabalhei profissionalmente, tinha quatorze anos. Essa era a idade legal para começar a trabalhar quando eu era jovem. Lembro que cheguei tarde na minha festa de aniversário porque estava lecionando em classes de reforço escolar para alguns estudantes.A partir de então, e hoje já tenho 48 anos, sempre, sempre estive vinculado à educação. O segundo grande elemento que me define é que eu acredito nas minhas duas grandes paixões: a paixão pelo conhecimento e a paixão pela ação social. Então, a paixão pelo conhecimento me levou a estudar muito. Sou doutor em Educação pela Universidade Autônoma de Barcelona e professor e pesquisador na mesma universidade. Necessito ler, necessito pesquisar, necessito dialogar com os acadêmicos. Não posso viver sem isso, mas tampouco posso viver sem a ação social e por isso a política, em seus diferentes formatos, tem sido sempre um aspecto muito importante para mim. Tenho me dedicado ao âmbito das ONG's, ao mundo dos escoteiros e à educação não-formal. Liderando o movimento dos escoteiros da Catalunha, me dediquei à luta contra o racismo. Fui o porta-voz e coordenador da organização SOS Racismo aqui em Barcelona. No âmbito da política internacional fui diretor do Centro Unesco da Catalunha e trabalhei em toda a Espanha. Atualmente sou secretário de Educação da Prefeitura 
de Barcelona, porque sempre penso que se as ideias não têm capacidade de ação social, então elas não podem transformar a realidade e que as ações sociais, sem as ideias, não transformam nada. Então, essas duas grandes paixões que sempre levei de um lado para o outro, entre uma temporada de ação acadêmica e uma temporada de ação política, de uma temporada de ação política a uma temporada de ação acadêmica e etc.

Isso é um pouco da minha trajetória. Fundei um partido político na minha escola quando eu tinha apenas 12 anos. Um partido de esquerda e ecologista. Eram os anos 80. Nessa época fazíamos campanhas ecologistas apesar de ainda não se falar nada do clima, nem do meio ambiente, muito menos de educação ambiental. Recordo também que essa paixão pela política não era pela política em si, pois eu nunca me interessei em ter um cargo ou mesmo alguma responsabilidade, meu interesse consistia em um serviço público para transformar a realidade. Então estes são os dois grandes elementos da minha carreira.

\section{JM/MCB - Explique seu atual cargo para as pessoas do Brasil possam compreender.}

ME - Atualmente as cidades podem ter um conselheiro (vereador) com funções de secretário. Nesses últimos quatro anos tivemos uma representação muito pequena de onze vereadores (do grupo político ao qual pertenço), para um total de quarenta e um aqui em Barcelona. A oposição política era muito grande e o governo era muito pequeno (governo que tem como prefeita/alcaldesa a Sra. Ada Colau, reeleita para mais uma gestão). Então as normativas da administração municipal de Barcelona autorizam que quando os governos são muito pequenos, o prefeito pode delegar algumas funções na figura de pessoas comissionadas. Uma pessoa comissionada é um vereador que não foi eleito, mas que tem as mesmas competências e obrigações de um que tenha sido eleito. Eu sou comissionado para educação, universidades, infância e juventude da Prefeitura de Barcelona.

JM/MCB - Seria o que no Brasil é o Secretário de Educação. Considerando o contexto de uma Europa cada vez mais diversa e multicultural, politicamente múltipla e que acolhe e ao, mesmo tempo, rechaça os estrangeiros: Qual a tua abordagem teórica e prática para compreender esse fenômeno hoje? Como tens trazido essas reflexões para o campo da política? Como Barcelona se relaciona com os imigrantes? Existem políticas educacionais específicas para isso?

ME - Barcelona é uma cidade catalã, uma cidade espanhola, mas também um centro europeu e, portanto, sendo uma cidade espanhola e europeia é uma cidade que vive as contradições das políticas vinculadas à imigração na Europa. E quais são essas contradições? Por um lado, nos âmbitos mais gerais e amplos da política e da administração da 
União Europeia e do Estado espanhol, se reservam as competências de gestão dos fluxos migratórios especialmente em temáticas de segurança e em ações de controle policial. Como, por exemplo, dar ou não permissão para residir no país? Dar ou não permissão para trabalhar? Colocar fronteiras, criar fronteiras? Perseguir as pessoas que não têm documentação? Tudo isso são competências que têm as grandes organizações (do Estado espanhol e da União Europeia). Enquanto isso, os níveis mais próximos dos cidadãos, da administração, dos governos regionais dos estados ou os governos locais precisam desenvolver uma política social para essas pessoas.

Aqui há uma contradição, pois, a política social a favor dos estrangeiros imigrantes necessita ser realizada em consonância com os instrumentos ligados ao controle de segurança e de fluxo. Por exemplo, aqui em Barcelona trabalhamos com menores estrangeiros que não possuem documentação e trabalhamos, educativamente, para que tenham um futuro, para que estudem, para que se formem, para que pratiquem esportes. Colocamos (a disposição) os recursos sociais da cidade, já que essas pessoas que são menores não podem ser expulsas. Porém no momento que elas completam dezoito anos, são adultos, maiores de idade, necessitam permissão para residir e trabalhar e para que possam ficar, isso não pode ser dado pelo Conselho da Cidade, só quem pode garantir é o Estado e o Estado pode demorar muito e, além disso, ainda é possível também que não o dê. Então uma pessoa que quando menor (em idade) tinha um bom percurso social, estudando, trabalhando, formando-se, praticando arte, cultura, esporte, no momento que tem dezoito anos passa a ser "ilegal". Eu não gosto, nem um pouco, do conceito de ilegal, eu falo de pessoas em situação irregular, mas geralmente as pessoas os conhecem como ilegais e os podem expulsar para o seu país de origem que, provavelmente, já não é seu país de origem. Porque, é bastante provável, que tenha nascido ou vivido desde muito pequeno na Espanha, que nunca tenha estado em seu país de origem. Então essa é uma forte contradição, porque os níveis mais gerais (mais altos da administração pública) têm o controle da segurança e dos processos de gestão de fluxo e os níveis mais básicos (da administração pública) como o da oferta de educação, não estão próximos, e nem sempre se posicionam em benefício da população imigrante com o direito social, educação, cultura, saúde, esporte. Esse é o grande drama, a grande tragédia que se passa em toda a Europa. Na atualidade isso vem se agravando cada vez mais. Os problemas estão mais graves. Por quê? Por dois grandes fatores: um ideológico e outro demográfico. O ideológico é o aumento da extrema direita na Europa, há uma onda crescente de extrema direita em todos os países europeus. A Espanha não escapa. Temos um partido que se chama VOX que tem recebido apoio internacional de grupos de ultra/extrema direita e agora é um partido que tem 24 deputados na Assembleia Nacional Espanhola, nosso Congresso dos Deputados. Tem 24 sobre 350 e estão se constituindo como uma força política chave para governar algumas regiões tão importantes como Madri e Andaluzia. Andaluzia é a região mais populosa da Espanha, com oito milhões e meio de habitantes, e Madri, a 
"O Mediterrâneo é a fronteira que separa o mundo pobre do mundo rico, e nele estão morrendo centenas de milhares de pessoas. Muitos refugiados conseguem salvar-se."

(Miquel Essomba)

"Nós temos feito, de 2015 até 2019, um centro aberto durante o dia, onde os jovens podem frequentar para comer, para tomar banho, para encontrar oportunidades de diversão, ócio e formação." (Miquel Essomba) mais importante politicamente, com seis milhões de habitantes, porque é a capital. Então, a extrema direita está defendendo, abertamente, a expulsão nos programas políticos das pessoas estrangeiras que não tenham documentação e o direito a selecionar os estrangeiros que eles querem. Essa é uma política totalmente contrária aos direitos humanos, que está condicionando todas as políticas. O que esse partido faz é mover à direita todos os demais partidos porque eles têm medo de perder votos e sabem que o voto de chamar ao medo, de que a imigração venha nos invadir, é um voto fácil e os partidos majoritários têm medo de perder esse voto para os grupos de extrema direita e, então, acabam se alinhando. Esse é um dos grandes problemas que tornam ainda mais grave a nossa situação atual. O segundo problema mais grave são as próprias pessoas refugiadas. Desde 2015 a Europa vive uma onda de pessoas refugiadas pela crise humanitária da Síria, mas também da Turquia, do povo Curdo, da Líbia do Norte, da África, do centro da África - algo muito grave. O Mediterrâneo é a fronteira que separa o mundo pobre do mundo rico, e nele estão morrendo centenas de milhares de pessoas. Muitos refugiados conseguem salvar-se. Eles estão chegando na Espanha e representam uma situação totalmente nova, isto é, algumas pessoas refugiadas que não chegam por motivos econômicos, mas por desespero, por problemas políticos e religiosos. Um percurso muito complexo, muito difícil. Por outro lado, temos muitos refugiados menores de idade que escaparam do seu país de origem, majoritariamente do Marrocos, por pura miséria. Há uma forte explosão demográfica no Norte da África, a população está crescendo de maneira totalmente descontrolada. As famílias pobres desses países, como Marrocos, Argélia, Tunísia, Líbia, Egito, têm em média, de oito a dez filhos, e assim a população se multiplica muito rapidamente. No ano passado vieram muitos desses jovens somente para a Catalunha (cerca de 3.500). Eles vêm do Marrocos, menores de 16, 17 anos, alguns têm 10,11, 13 anos e este ano as autoridades da Catalunha, isto é, o governo calculou que irão chegar mil a mais, que irão se juntar aos 3.500 do ano passado, aos do outro ano e etc. Esses menores não falam espanhol e vivem em situação de extrema pobreza, muitos deles - principalmente aqueles com 10,11, 12, 13 anos - o sistema social não tem capacidade de acolhê-los e muitos deles acabam vivendo nas ruas como indigentes, com tão pouca idade. Quando alguns deles são integrados aos centros sociais, para ajudá-los (são meninos, digo, majoritariamente meninos, $95 \%$ são homens), acabam fugindo, porque o desenho de funcionamento desse sistema não foi pensado para pessoas tão diferentes, com modos de vida distintos das instituições. Então esteé um problema muito grave, que em 2019, no outono, vai gerar problemas muito graves.

\section{JM/MCB - E vocês criaram políticas ou programas educacionais para isso?}

ME - Nós temos feito, de 2015 até 2019, um centro aberto durante o dia, onde os jovens podem frequentar para comer, para tomar banho, para encontrar oportunidades 
de diversão, ócio e formação. Um centro de informação sobre coisas que eles podem fazer e esse centro está ajudando, o que acontece é que está completamente sobrecarregado porque sua capacidade não é suficiente para a demanda. Também abrimos uma escola de segunda oportunidade, que deve permitir que esses jovens tenham uma segunda oportunidade de frequentar a escola ou de participar de uma formação. Fizemos um programa denominado Bamba para trabalhar questões de integração de jovens imigrantes e crianças na educação não formal, nas atividades de lazer, porque elas não apenas precisam apenas ir à escola, elas também precisam frequentar as atividades de tempo livre.

\section{JM/MCB - Vocês sabem quantos estudantes são imigrantes ou refugiados, chegam e conseguem ficar na escola?}

ME - Não. Não temos esses dados porque é francamente difícil, eles se mudam, escapam. Há também outro programa denominado Prometeus que serve como mentoria e transição para a educação superior. Também descobrimos que muitos jovens de famílias estrangeiras têm excelente formação. Eles obtêm bons resultados acadêmicos, passam nas seleções acadêmicas, mas não vão para a universidade e não é apenas por falta de recursos financeiros, mas também porque em seu universo mental existem barreiras invisíveis que lhes fazem crer que não pertencem a esse mundo do ensino superior. São estes os programas principais que trabalhamos.

\section{JM/MCB - Como acontece a convivência intercultural? Os recém-chegados trazem sua bagagem religiosa, de hábitos culturais e encontram outros. Como isso se dá?}

ME - Temos basicamente dois programas, um programa geral, que é o que tem realizado o Conselho Municipal desde a área da imigração que se chama Programa Contra Rumores, cujo intuito é trabalhar a desconstrução de estereótipos e preconceitos contra as pessoas estrangeiras. Então há uma série de materiais de formação, há uma equipe de voluntários e também profissionais que estão formados para trabalhar, ir aos bairros, aos mercados, as praças dos bairros e atuar no sentido de desconstruir preconceitos e estereótipos. No âmbito mais concreto da infância e da educação, temos um programa chamado Koinos - que significa casa de acolhida em grego (na perspectiva do comum, compartilhado entre todos). Durante três anos este programa elaborou ferramentas para o respeito e a formação da diversidade linguística e o plurilinguismo nas escolas de educação obrigatória. Fizemos uma experiência piloto em três escolas, mas também elaboramos os materiais que estão disponíveis em várias línguas na página da web - em português também, porque foi no marco do programa Erasmus Kloss e um dos sócios europeus era a Universidade de Aveiro. 
"Barcelona tem

73 bairros. Neles

vivem e convivem

mais de cem

nacionalidades, $o$ que dá uma ideia da diversidade e heterogeneidade da cidade."

(Miquel Essomba)
JM/MCB - No Brasil esses esforços têm uma conotação diferente, porque somos um país de imigrantes. Somos imigrantes. Somos de fora. Temos os descendentes dos povos originários. Proporcionalmente poucos pois muitos foram assassinados nos processos de colonização. Houve genocídio como em toda a América, de norte a sul.

Os povos originários da África vieram como escravos. Infelizmente, temos um preconceito muito grande com as pessoas negras. Primeiro por que há uma negação do racismo. Muitas pessoas afirmam que não há racismo no País, mas os afro-brasileiros sempre foram muito marginalizados e hoje apesar de todas as políticas de cotas feitas no Governo Lula (2003-2010), os estudantes negros seguem sempre muito excluídos. Os afrodescendentes nunca foram compreendidos como pessoas com os mesmos direitos das pessoas brancas. Eles não iam à escola, não porque a escola não pudesse ser frequentada por afrodescendentes, mas porque dentro também de seu universo mental havia tantas barreiras que eles simplesmente não iam e isso era considerado natural na sociedade. E é claro que a oferta de vagas para estes estudantes nunca foram proporcionais a demanda. Apesar das legislações garantidoras de acesso e permanência para todos/ todas a dura realidade sempre foi de muita exclusão.

JM/MCB - Agora falemos do Plano de Educação de Barcelona: A educação em Barcelona, uma revolução silenciosa (2015/2019). Observa-se pelo título que a educação pública é o eixo da estrutura e do comprometimento da cidade e da Prefeitura de Barcelona sendo apresentada como o motor da transformação social. Perguntamos: como no contexto do planejamento de uma cidade como Barcelona, considerando o contexto capitalista de natureza excludente a que estamos todos submetidos, vocês conseguem manter a força da educação pública e seu valor como transformação social?

ME - Barcelona é uma cidade muito compacta e, nesse sentido, muito mediterrânea. Não é uma cidade extensa. Hoje eu escutava os últimos dados demográficos de Barcelona e a chefe do serviço de estatística explicava que Barcelona tem 73 bairros. Neles vivem e convivem mais de cem nacionalidades, o que dá uma ideia da diversidade e heterogeneidade da cidade. Barcelona é muito diversa e também é uma cidade desigual. Existem fortes desigualdades. Dependendo do território da cidade, é possível calcular que entre os bairros com maior poder aquisitivo econômico e os bairros mais populares, no sentido de menor poder aquisitivo, pode haver até uma diferença na expectativa de vida de cerca de 10 anos. É forte, muito forte. É um indicador que conhecemos há quatro ou cinco anos e temos que pensar muito em como mudá-lo. Quando passamos isso para o campo da educação, também vemos as desigualdades. Os distritos com maior concentração de educação privada são os distritos dos bairros mais ricos e os distritos onde há mais educação pública são os dos bairros mais pobres. 
JM/MCB - Em porcentagem quanto é de educação pública e quanto é de educação privada?

ME - Essa é uma questão que faz de Barcelona uma anomalia, não só na Catalunha, mas em toda a Europa, porque viemos de uma situação histórica que torna a educação privada majoritária em Barcelona. Cerca de $55 \%$ dos alunos matriculados na educação obrigatória estão em escolas privadas. Isso faz da educação de Barcelona uma anomalia, porque na maioria dos países da Europa a educação é majoritariamente pública/estatal.

\section{JM/MCB - Seria uma herança do regime de Franco?}

ME - Claramente, a Igreja Católica é muito presente na educação da classe média e isso se mantém apesar de 40 anos passados desde o fim do franquismo. Veja uma geração depois e ainda não foi solucionado o problema porque não houve uma aposta em construir progressivamente uma educação pública e terminar com isso de dar dinheiro público para que as escolas privadas exerçam uma função pública. Isso não tem funcionado.

\section{JM/MCB - Por esse motivo o Plano dedica-se a educação pública?}

ME - Talvez por isso nós apostamos na educação pública. Porque a educação pública é a única educação que é inclusiva e promove a equidade. Inclusiva porque por ser pública, não pode colocar barreiras nem fronteiras para que nenhuma menina, nenhum menino, nenhuma pessoa adulta seja discriminada e se possa dizer "tu sim, tu não". Nas escolas privadas há um elemento de seleção, mais ou menos explícito, se a escola é privada e sem dinheiro público, podem selecionar diretamente e dizer "tu sim, tu não", porém se é privada com dinheiro público não podem fazer essa diferenciação. Mas há uma seleção invisível. Embora, por exemplo, uma escola religiosa católica particular deva acolher um filho de uma família muçulmana, a família muçulmana não se sentirá muito confortável nessa escola. Legalmente, essa família tem o direito de frequentar essa escola, mas simbolicamente, essa família se sente expulsa, porque eles têm uma religião e nessa escola se pratica outra religião. Tanto que ainda temos escolas privadas que segregam por sexo, escolas só para meninos e só para meninas, e recebem dinheiro público para isso.

\section{JM/MCB - Essa será uma luta longa?}

ME - Não, nós vamos tentar que se acabe no ano que vem! A escola pública não segrega por religião, por sexo, por classe social. E por outra parte, a equidade, esse fator de correção é importante. As escolas privadas têm a tendência a promover sempre os mais competentes, os mais preparados, porque querem captar na lógica do mercado, as
" $55 \%$ dos alunos matriculados na educação obrigatória estão em escolas privadas. Isso faz da educação de Barcelona uma anomalia..." (Miquel Essomba)

"Sem dúvida, a escola pública, a educação pública não promove a competição. Ela visa promover a cooperação." (Miquel Essomba) 
melhores famílias e os melhores alunos. Em uma lógica de competição. Sem dúvida, a escola pública, a educação pública não promove a competição. Ela visa promover a cooperação. É uma cooperação porque romper as desigualdades não pode ser a escolha de apenas um território, mas sim a cooperação de várias escolas, dos serviços de apoio local, da administração regional. Todos têm que cooperar, dando mais para quem menos tem. É uma correção: se tu tens mais problemas, então tu necessitas de mais recursos. Rompendo com a lógica neoliberal, como a política de Tony Blair, nos anos 90, de dar mais para aqueles que conseguem os melhores resultados.

JM/MCB - ...a meritocracia, que é exatamente o que se começa a implantar no Brasil neste ano. Então o sentido de transformação tem a ver com o sentido de cuidar, isto é, a escola pública como um espaço que garante a equidade e a inclusão. $O$ que destacarias da perspectiva de uma revolução silenciosa sobretudo considerando a ideia de educação por toda a vida - a educação obrigatória, seu entorno e o que vem depois dela? O que tu destacarias do Programa?

ME - Nós temos nos concentrado muito na educação obrigatória, mas também temos pensado muito na educação não formal, ao longo da vida, e aquela que acontece ainda antes da educação obrigatória, educação para os três, quatro anos. Temos no sistema educacional o primeiro ciclo da educação infantil, 0 a 3 anos; o segundo ciclo da educação infantil, dos 3 aos 12 anos que está compactado com os seis anos da educação primária e, depois, temos a educação secundária obrigatória e pós-obrigatória. A educação secundária tem duas etapas: a obrigatória, que vai dos 12 aos 16 anos e depois a pós-obrigatória, dos 16 em diante. São quatro anos de educação secundária obrigatória. E não há escolha profissional nessa etapa. Após os 16 anos o estudante opta pelo bacharelado ou pela formação profissional. Temos apoiado fortemente as escolas de bairros que passam por dificuldades. A educação profissional é também uma prioridade, pensando em modos de diversificá-la, porque a educação profissional está muito desprestigiada em Barcelona.

‘... unimos a educação primária

à secundária,

porque na transição

entre uma e outra

muitos desses alunos se perdiam."

(Miquel Essomba)

\section{JM/MCB - E aconteceram ações específicas para a escola secundária?}

ME - Na educação secundária nós fizemos uma aposta muito forte para fazer uma compactação da escola primária e secundária. Temos uma estratégia geral na cidade que chamamos de plano dos bairros, que é uma estratégia para dezoito áreas social e economicamente desfavorecidas. Criamos, por exemplo, três novos centros de formação profissional para conectar mais diretamente e melhor a escola com o mercado de trabalho. Fizemos também três institutos novos, onde unimos a educação primária à secundária, porque na transição entre uma e outra muitos desses alunos se perdiam. Compactando isso temos bons resultados no processo de transição entre as etapas. 
JM/MCB - Qual a relação entre a prefeitura e a universidade?

ME - Quando chegamos ao governo nós nos demos conta que as universidades se relacionavam com a prefeitura de forma muito desorganizada e de forma muito pontual, para alguns pequenos projetos, e também de forma individual. A cidade com as suas próprias coisas, sem entrar em contato com as universidades. Nós achamos que essa governança muito fragmentada não era boa nem para a prefeitura, nem para as universidades. Então começamos a construir uma forma de relação, onde trabalhamos com as universidades juntas, depois em separado e fizemos planos globais, elencando objetivos concretos, vimos quais eram os públicos e trabalhamos por um objetivo comum, para que Barcelona deixe de ser uma cidade com universidades para ser uma "cidade universitária". Tivemos como referência algumas cidades, como Salamanca, que é uma cidade pequena, onde a universidade cumpre um papel muito importante. É uma cidade que se sente universitária. Então abrimos um caminho para começar a trabalhar nessa direção. Para além da sangria do turismo, ser também uma cidade universitária. Estamos trabalhando há quatro anos com as universidades para isso.

\section{JM/MCB - Através de projetos, editais?}

ME -Temos um espaço, um conselho assessor de universidades, que é como um espaço de encontro entre as universidades e as estruturas municipais. E depois há três grupos de trabalho sobre infraestrutura, outro sobre lifelong learning e outro sobre solidariedade. Então esses três grupos trabalham para desenvolver projetos.

JM/MCB - Temos poucas horas diárias de escola no Brasil, em geral quatro horas. Quantas horas há aqui e qual a relação com o entorno e com uma perspectiva de formação humana integrada que não se limite as disciplinas escolares, sobretudo aquelas valorizadas pelos rankings internacionais como o Pisa?

ME - Na escola primária depende se é pública ou privada, na escola pública são cinco horas diárias e na escola privada, às vezes, há uma sexta hora. Nós pensamos que mais quantidade não traz mais qualidade, não podemos dizer, por exemplo, que os alunos das escolas privadas são melhores que os das escolas públicas porque tem uma hora a mais de aulas todos os dias. As pesquisas nos dizem que as escolas públicas têm os melhores alunos.

JM/MCB - E há uma preocupação em ampliar as atividades formativas para além das cinco horas?
"Trabalhamos

por um objetivo

comum, para que

Barcelona deixe de

ser uma cidade com

universidades para

ser uma 'cidade

universitária'."

(Miquel Essomba) 
ME - Há atividades extraescolares de arte, esportes, de música.... Essas atividades não são compactadas, elas são divididas, normalmente em três horas pela manhã e duas horas à tarde. A maioria das crianças permanece na escola ao meio dia, mas tem um tempo para descansar. Atualmente $80 \%$ das crianças permanecem nas escolas, as outras vão para a casa para almoçar. Quando nós entramos havia um deficit muito expressivo de bolsas de estudo (que permitem a permanência para além dos horários obrigatórios) que logo tratamos de ampliar. Havia 17.000 sendo que a necessidade era de 27.000. Conseguimos então 10.000 bolsas a mais. Barcelona, nos últimos quatro anos tem dado conta da total incapacidade do governo da Catalunha de financiar políticas sociais. Então como o governo não financiava essas bolsas, a prefeitura tem financiado, mas essa não é a normalidade.

\section{JM/MCB - Há um movimento forte de pais e mães na Catalunha. Como funciona?}

ME - Praticamente cada escola tem sua própria associação de pais e mães, chamadas de distintas maneiras, e elas têm um papel muito importante na escola. Porque, em primeiro lugar, participam os órgãos do governo da escola. Todas as famílias têm um espaço de representação, o que é muito importante. Por exemplo, nas atividades administrativas que a escola não consegue realizar com autonomia, as famílias podem contribuir: há associações de famílias, por exemplo, responsáveis pela merenda da escola ou pelas atividades extracurriculares.

“... de 1931 a 1936,

houve um impulso muito forte na educação pública e as pedagogias que havia nessas escolas eram pautadas no princípio das pedagogias ativas."

(Miquel Essomba)

\section{JM/MCB - A obra e a escola de Francesc Ferrer y Guardia foram muito importantes para Barcelona, uma escola libertária e moderna. Creio que foi a primeira escola do movimento pedagógico renovador da Espanha. O que resta de Ferrer y Guardia nas escolas públicas de Barcelona?}

ME - Resta uma Fundação. Barcelona celebrou neste mandato os 100 anos da época mais brilhante da escola pública na cidade, porque a comissão de cultura da Prefeitura de Barcelona, em 1916, construiu as primeiras escolas públicas para os meninos e meninas dos bairros da cidade, para a sua educação, onde se lhes dava de comer e se cuidava da sua higiene e da sua saúde. Depois, durante a segunda república espanhola, de 1931 a 1936, houve um impulso muito forte na educação pública e as pedagogias que havia nessas escolas eram pautadas no princípio das pedagogias ativas. Montessori esteve em Barcelona, chegando a dar formação. Ferrer Y Guardia, é uma lástima que tenha morrido fuzilado, deixou uma forte presença do que foi a escola moderna. Há muitos pedagogos que tiveram papéis muito importantes. Porém, com o franquismo destruiu-se todas essas pedagogias ativas, pois, como disse, o que importava era a educação cristã e católica. Então no final dos anos sessenta, quando a ditadura franquista já estava morrendo, 
começam a acontecer movimentos de professores que se sentiram valentes e fortes para recuperar essas pedagogias. Hoje, quarenta anos depois, podemos dizer que essa pedagogia ativa está viva na escola pública e é muito apreciada pelas famílias. E quando nós construímos uma nova escola pública, já sabemos que ela terá essa pedagogia.

JM/MCB - A cidade tem programas de formação continuada de professores, as universidades participam dessa formação?

ME - Como prefeitura não podemos participar da formação inicial dos professores pois esta é uma competência exclusiva das universidades, mas somos responsáveis pela formação permanente de nossos professores. Então, temos um programa que se chama Redes para a mudança educativa, que atende todas as escolas da cidade. Trata-se de um programa de tutoria, um programa de apoio para professores, que uma vez por semana se encontram com mentores e tutores e trabalham com os conteúdos da escola a partir da inovação educativa.

JM/MCB - As universidades estão embasadas nos princípios das metodologias ativas para a formação de professores?

ME - Sim, mas há um pouco de tudo. Evidentemente nas universidades há professores que trabalham com as pedagogias ativas.

JM/MCB - O que pensas sobre as cidades educadoras, essa rede ou associação internacional que a cidade de Barcelona criou e coordena desde 1990?

ME - Eu acredito que o grande valor da Cidade Educadora seja a educação comunitária, que todas as pessoas sejam agentes da educação e depois tomar consciência de que a educação de lifelong learning não passa simplesmente por escolas, ela necessita ser dada de maneira global. O mundo das redes sociais, o mundo digital, o mundo da tecnologia necessita de mão de obra, por isso o trabalho compartilhado, em rede, onde todos se sintam educadores é muito importante. Se quisermos que a educação seja um motor de renovação social, um espaço de construção de cidadania, que defenda fundamentalmente os valores de democracia necessitamos de redes, porém, se consideramos que a educação esteja apenas a serviço do mundo do trabalho, então as redes educadoras devem desaparecer.

JM/MCB - Para concluir, te propomos pensar educação e democracia em um mundo em convulsão. Viemos de um país que vive uma situação muito extrema, com um governo com posições ultraconservadoras, com o intuito de armar a população, valorar
"Como prefeitura

não podemos

participar da

formação inicial

dos professores

pois esta é uma

competência

exclusiva das

universidades, mas

somos responsáveis

pela formação

permanente..."

(Miquel Essomba) 
"Temos que

valorizar a

importância da

escola para reforçar

a democracia em

si porque muita

gente aprendeu

sobre democracia

através da escola."

(Miquel Essomba)

"Paulo Freire está muito presente no discurso pedagógico de Barcelona. Na

formação inicial de professores, ninguém sai sem ter

lido A Pedagogia do Oprimido..."

(Miquel Essomba) a violência como modo de relação social, excluir direitos sociais, excluir a perspectiva de igualdade de gênero. É um mundo convulsionado, um mundo, lembrando o Eduardo Galeano, de patas arriba. Como vês a educação e a democracia nesse mundo?

ME - A escola é um elemento que está situado nesse âmbito de tensão entre uma educação para o mercado ou uma educação social. Algumas forças políticas, ideológicas, econômicas movem o mundo em direção a um conservadorismo moral e um neoliberalismo econômico agressivo e, portanto, entendem a escola como um instrumento do mercado, onde os alunos e as famílias são clientes e é preciso haver competição para que o sistema funcione. Mas também temos a educação social, a educação para a cidadania, que entende que a escola é um espaço para aprender a ser livre, para emancipar-se e adquirir conhecimentos para que cada cidadão possa ser livre com os demais. Essa tensão está muito presente. A Unesco, em 2015, fez um informe onde tentava de uma maneira, para mim pouco satisfatória, aproximar as duas questões: que o sistema educativo seja um espaço, sobretudo, social, para construir a cidadania, mas também um espaço para desenvolver competências para o mundo do trabalho e o mundo econômico. Defendia que isso se daria mediante uma formação em instituições públicas, privadas e mistas. Eu creio que isso não é possível, isso geraria uma desvalorização do setor público e a valorização do privado. A experiência está nos ensinando isso. E isso tem muita importância, porque quando a escola é como um supermercado, aí tu começas a comprar cursos, tu pagas por um título, mesmo que sejas competente. Nessas escolas não há ênfase na educação para a democracia. A escola precisa formar cidadãos e cidadãs e não trabalhadores para o mercado de trabalho, então formar cidadãos quer dizer que tu incorporas na governança da escola elementos democráticos, como assembleias de alunos, participação em conselhos da cidade, quer dizer também que a escola educa através de uma pedagogia ativa - que é também democrática, porque pergunta primeiro ao aluno o que ele quer aprender. $\mathrm{Na}$ Espanha, o fato de incluir as famílias foi muito importante. Existia uma barreira muito significativa na escola que não se abria, porque para muita gente adulta, participar de uma assembleia de mães e pais da sua escola ou na comissão de trabalho da sua escola era a primeira experiência democrática que tinham em suas vidas. Um espaço onde se encontra com outras pessoas para dialogar sobre problemas, tomando decisões e criando projetos. Temos que valorizar a importância da escola para reforçar a democracia em si porque muita gente aprendeu sobre democracia através da escola.

JM/MCB - Paulo Freire tem sido muito atacado no atual contexto brasileiro apesar do reconhecimento que tem mudo afora. Qual a importância de Paulo Freire no universo educacional da cidade de Barcelona? 


\section{ME - Paulo Freire está muito presente no discurso pedagógico de Barcelona. Na for-} mação inicial de professores, ninguém sai sem ter lido A Pedagogia do Oprimido, ninguém sai sem entender o conceito de educação bancária e de conscientização e, sobretudo, ele é muito importante na educação de pessoas adultas. Nas escolas que são de adultos, inovadoras, potentes, a pedagogia de Freire tem muito peso e muito valor. ${ }^{3}$

\section{Notas}

1 Escolhemos guardar na transcrição elementos da oralidade pois a entrevista foi uma conversa gravada e posteriormente transcrita.

2 Miguel Angel Essomba i Gelabert (1971) é mestre em Psicologia, doutor em Pedagogia e professor do Departamento de Pedagogia Aplicada da Universidade Autônoma de Barcelona. Dirigiu o Mestrado em Educação Intercultural e é diretor da equipe de Pesquisa sobre Diversidade e Inclusão em Sociedades Complexas e da Cátedra Unesco de Educação Comunitária. Filho de pai camaronês e mãe catalã, viveu o racismo cotidianamente na Espanha. Até 2003, foi porta voz da ONG SOS Racismo, com mais de 30 anos de existência. Também foi diretor do Centro Unesco da Catalunha e consultor da Comissão Europeia sobre Educação e Diversidade (OCDE). Também foi professor Visitante do Institute of Policy Studies in Education, da Universidade Metropolitana de Londres e de outras universidades europeias e latino-americanas. É coordenador geral da rede Sirius de políticas sobre imigração e educação da União Europeia. Publicou livros sobre a gestão da diversidade cultural (Graó, 2008) e imigração e interculturalidade na cidade (Graó, 2012). Em 2012 entrou para a política, candidatou-se a vereador independente em Barcelona e, em 2015, assumiu o cargo de secretário Municipal de Educação. No contexto do governo local de uma importante cidade europeia, pode implementar as ideias que vinha desenvolvendo. No informe intitulado La educación en Barcelona, una revolución silenciosa (2015-2019), publicado pelo Instituto de Educación del Ayuntamiento de Barcelona, a educação pública é apresentada como "motor da transformação social". Desde a educação infantil até a universidade, a perspectiva que se coloca é a de ampliação de acesso e qualidade: "Educacion Pública: más cantidad, más calidad, más equidad, más democracia, más universidad". Ao mesmo tempo em que se afirmam as bases sobre as quais a própria democracia que vivem foi construída, abrem-se - a partir de princípios bem claros - para pensar a articulação de redes de apoio, redes de aprendizagem, redes de acolhimento, sem que o poder público abdique do seu papel. 